\title{
A imagem do governo brasileiro pelo Jornal Nacional da Rede Globo nas eleições presidenciais de 2002 e 2010
}

\author{
The Brazilian government image by Rede Globo's news from Jornal \\ Nacional program at Presidential Election in 2002 and in 2010
}

Florentina das Neves Souza

Doutora em Ciências da Comunicação pela Escola de Comunicações e Artes da Universidade de São Paulo (ECA/USP), docente e pesquisadora da Universidade Estadual de Londrina (UEL), Londrina, PR - Brasil, e-mail: flora@uel.br

\section{Resumo}

O Jornal Nacional, maior telejornal em estrutura e audiência da televisão brasileira, é o foco deste artigo. O estudo analisou o perfil da cobertura do programa em duas eleições presidenciais similares: 2002 e 2010. Investigou-se a abordagem do telejornal para assuntos de governo e para os pré-candidatos, vinculados ao governo, no período que antecedeu a definição das candidaturas. O corpus foi constituído por reportagens constantes de edições dos meses de abril, maio e junho. Os elementos discursivos foram levantados por meio de metodologia com pontuação de dados quantitativos e qualitativos, além de seleção das valências. Tanto em 2002 como em 2010, os presidentes Fernando Henrique Cardoso (FHC) e Luiz Inácio Lula da Silva (Lula), respectivamente, ambos cumprindo segundo mandato, apoiaram e defenderam seus candidatos, além de trabalharem por eles. Esta pesquisa investigou como o telejornal de maior influência e audiência junto à opinião pública brasileira se comportou em cada um desses pleitos.

Palavras-chave: Jornal Nacional. Eleições presidenciais brasileiras. Eleições 2002. Eleições 2010.

\begin{abstract}
Jornal Nacional, the biggest Brazilian television news in structure and audience, is the focus of this article. This study analyzed the profile of program coverage about two similar presidential elections: 2002 and 2010. It was investigated the TV new's approach for government subjects and for the pre-candidates linked to government in the period that preceded the definition of election's applications. The corpus comprises articles contained in the editions of April, May and June. Through a scoring methodology of qualitative and quantitative data, the discursive elements used were evaluated. Both in 2002 and in 2010, the presidents Fernando Henrique Cardoso (FHC) and Luiz Inácio Lula da Silva (Lula), respectively, both serving his second term, supported and defended
\end{abstract}


their candidates, besides, working for them. This paper researches how the most influential TV news program for Brazilian's public opinion worked in each one of these claims.

keywords: Jornal Nacional. Brazilian's presidential elections. 2002 elections. 2010 elections.

\section{Introdução}

As eleições presidenciais no Brasil são períodos fundamentais para o país e envolvem toda a sociedade brasileira. E o momento, também, no qual se evidencia o comportamento dos meios de comunicação na formação da opinião pública. No entanto, é durante os meses que antecedem a definição e registro das candidaturas que se verifica a construção, por meio da mídia, da imagem favorável ou não, aos candidatos e partidos.

A análise desenvolvida para este artigo tem como recorte as eleições presidenciais de 2002 e 2010, nos meses de abril, maio e junho. A proposta foi de investigar e interpretar o conteúdo do Jornal Nacional (JN) na abordagem de assuntos referentes aos governos Fernando Henrique Cardoso e Luiz Inácio Lula da Silva e os candidatos dos dois presidentes no período de pré-registro de candidaturas nas eleições já citadas, José Serra e Dilma Rousseff.

Entendemos aqui como conteúdo sobre as eleições dos telejornais não somente as agendas de candidatos, mas o conjunto de mensagens transmitidas pelo telejornal relacionado a política e tema específico de eleições. A análise desenvolvida no artigo foi norteada pelas hipóteses de que o JN enquadrou as matérias sobre o governo e os candidatos do governo em 2002 e 2010, de acordo com o ponto de vista, o que inclui não só interesses pessoais, mas a própria definição da linha editorial com recortes em relação às fontes; o telejornal mostrou uma cobertura parcial, fato importante na definição de candidaturas e no resultado das pesquisas eleitorais; antes mesmo do início da campanha, o Jornal Nacional construiu um cenário específico para beneficiar pré-candidatos e marginalizou outros ao excluir pontos de vista importantes e valorizar momentos degradantes de cada um.

Recorde-se que em 1989 a cobertura das eleições presidenciais no Brasil, principalmente no segundo turno, foi objeto de discussão pelos críticos da mídia no episódio envolvendo a edição do debate entre os dois candidatos no segundo turno, exibida no JN, da Rede Globo, na véspera da eleição. Isso teria favorecido o candidato Fernando Collor de Mello, em detrimento de Luiz Inácio Lula da Silva.

Essa gênese do telejornal e o passado de enquadramentos unilaterais em coberturas políticas que favoreceram candidatos, aliados com o poder político em vigor, levantaram as hipóteses de que, a partir de 1989, toda a cobertura eleitoral nos principais telejornais poderia ser enviesada.

$\mathrm{Na}$ análise da cobertura da eleição presidencial de 2002, verificou-se a maior visibilidade da mídia em uma eleição. Já no início do ano, era possível perceber que as eleições de 2002 seriam enfatizadas pela mídia com uma cobertura extraordinária, mesmo antes das convenções partidárias. De acordo com Aldé (2004, p. 107), a eleição presidencial de 2002 tornou-se assunto relevante nas páginas de política dos principais jornais e ganhou progressivamente mais espaço. Nos últimos dois meses da disputa, matérias especiais mobilizavam positivamente o noticiário e contribuíram para o envolvimento eleitoral em geral (NEVES, 2008).

O estudo apresentado aqui destaca duas eleições parecidas. Em cada uma delas, o Presidente da República, em um segundo mandato, tenta eleger como sucessor um ex- ministro de sua confiança e do seu partido. Outra similaridade é em relação à presença do candidato José Serra, do PSDB, que, em 2002, representava a situação como candidato do então presidente Fernando Henrique Cardoso e, em 2010, era o candidato da oposição. Além disso, pela terceira vez consecutiva os candidatos do Partido Socialista Democrático Brasileiro (PSDB) e do Partido dos Trabalhadores (PT) polarizaram a disputa em pleito presidencial para o cargo máximo do país.

A coleta de dados recortou, em 2002, 22 telejornais dos 78 exibidos nos meses de abril, maio e junho, período que antecedeu o prazo estipulado pela justiça para registro dos candidatos. Em 2010, 
foram analisados 20 programas em cada um dos três meses, e foi possível, por meio da coleta de dados e da metodologia do enquadramento (ENTMAN, 1993), identificar como os assuntos referentes ao governo de Fernando Henrique Cardoso, em 2002, e de Luiz Inácio Lula da Silva, em 2010, foram destacados e qual o tratamento dado aos pré-candidatos que representavam estes governos (Tabela 1).

Tabela 1 - Telejornais e matérias analisados

\begin{tabular}{lcc}
\hline & 2002 & 2010 \\
\hline Telejornais exibidos & 78 & 78 \\
Telejornais analisados & 22 & 60 \\
\hline
\end{tabular}

Fonte: Acervo pessoal.

Para estudar comparativamente como o JN cobriu os assuntos de governo no período anterior à definição das candidaturas em 2002 e 2010, utilizamos o conceito de enquadramento empregado pelos Núcleos de Pesquisa em Mídia e Política das Universidades Brasileiras. Para o pesquisador Mauro Porto (2001), o conceito de enquadramento é usado para definir os princípios de seleção, apresentação e ênfase usados para organizar os noticiários. Embora não se avaliará a cobertura dos candidatos, pretende-se mostrar se houve uma seleção e interpretação de temas e enquadramento centralizado na personalidade dos presidentes, nesses dois casos.

\section{Eleições 2002}

A disputa presidencial de 2002 evidenciou o discurso da mudança. Ao contrário de 1994 e 1998 , quando - apesar de uma conjuntura econômica ruim - o governo FHC alcançou um balanço satisfatório na campanha, percebeu-se o descontentamento da população frente às situações de desemprego, insegurança e instabilidade da economia.

No começo de 2002, o cenário eleitoral começou se projetar. De um lado, o governo precisava manter unidos os partidos e as propostas que reelegeram Fernando Henrique; do outro, a oposição, representada principalmente pelo Partido dos Trabalhadores (PT), tentava pela quarta vez eleger
Luiz Inácio Lula da Silva. Já eram consideradas certas as candidaturas de Lula; a do ex-governador do Ceará, Ciro Gomes, do Partido Popular Socialista (PS); a candidatura do então governador do Rio de Janeiro, Anthony Garotinho, do Partido Socialista Brasileiro (PSB); a da governadora do Maranhão, Roseana Sarney, do Partido da Frente Liberal (PFL); do governador de Minas Gerais, Itamar Franco, pelo Partido do Movimento Democrático Brasileiro (PMDB); e de José Serra, pelo Partido da Social Democracia Brasileira (PSDB).

No período analisado, o JN destacava as alianças de candidatos com outros partidos e apoio de políticos. José Serra teve destacado o apoio recebido do PFL, citado duas vezes em uma mesma matéria. Para Garotinho, o apoio de Maluf, destacado pelo $\mathrm{JN}$, não teve a mesma valência positiva que para Serra, porque ligava seu nome a um político que já teve problemas com a Justiça.

As matérias sobre o governo enfatizadas pelo telejornal no período analisado em 2002 foram pautadas pela economia. O destaque foram as reportagens e comentários sobre a crise na Argentina, o aumento do dólar e do risco Brasil, invariavelmente de evidência negativa para os candidatos da oposição, já que apontavam, por exemplo, a possibilidade de aumento do risco Brasil em função de depoimentos entendidos como ameaçadores à estabilidade econômica.

Eleja um presidente que se ache acima do Congresso. Ou um presidente abaixo do Congresso, sem maioria para governar. Ou um presidente machinho: "Eu boto pra quebrar". Ou que diga: "Dane-se o mundo; só existe o Brasil". Ou então: "Dane-se o Brasil, só existe o mundo". Ou um populista: "Eu prometo tudo a todos, pois Deus me mandou". Ou então: "Democracia é coisa de burguês e ajuste fiscal é bobagem" (JABOR, 2002).

Os indicadores divulgados hoje pelo IBGE mostram as transformações do país entre os anos de 91 e 2000. O presidente Fernando Henrique Cardoso, que assumiu o cargo no meio da década, analisou o resultado da pesquisa. O presidente Fernando Henrique destacou os pontos que achou mais importantes do Censo 2000. Quase todas as crianças de sete a 14 anos 
na escola; mais casas com rede de esgoto, água e coleta de lixo. Queda na mortalidade infantil (JORNAL NACIONAL, 8 de maio de 2002).

Em entrevistas concedidas em duas edições analisadas do telejornal, Armínio Fraga, então presidente do Banco Central (BC), fez ressalvas sobre os candidatos de oposição. O Ministro da Fazenda Pedro Malan foi exibido relacionando a crise aos candidatos de oposição. Em quase todos os telejornais do mês de maio, apareceram matérias sobre a Argentina e "falas" de Malan e do candidato apoiado pelo governo, José Serra, nas quais destacaram que o Brasil poderia se transformar "na Argentina". Serra destacou várias vezes: "é preciso ter a casa arrumada senão vira a Argentina".

Esses enquadramentos negativos para os candidatos de oposição tiveram seu "auge" no dia 13/05/2002, quando o JN exibiu entrevista concedida por Armínio Fraga, ao programa Bom Dia Brasil, também da Rede Globo, o que se considera, no jargão jornalístico, uma matéria "requentada", normalmente vinculada à linha editorial da empresa e repetida para enfatizar a público diverso do inicialmente previsto. $\mathrm{O}$ presidente do $\mathrm{BC}$ destacou que os bancos estrangeiros deviam reduzir os investimentos no Brasil porque o candidato do PT liderava as pesquisas eleitorais.

A parte editada da entrevista para o JN teve mais de dois minutos e uma repercussão negativa para os candidatos de oposição. O Ministro dizia que "não devíamos esquecer o passado" (JORNAL NACIONAL, 13 de maio de 2002); insinuava que, se houvesse mudança na direção do governo, tudo poderia mudar e a estabilidade estaria ameaçada. "É comum os candidatos prometerem e dizerem que tudo é viável ao mesmo tempo e já. O medo é que, por falta de entendimento, você entra em uma trajetória e vai dando vários passos na direção errada" (JORNAL NACIONAL, 13 de maio de 2002). A entrevista destacada pelo telejornal suscita o medo da mudança.

O Jornal Nacional destacou também na agenda do governo a lei de responsabilidade fiscal e a possibilidade de volta da inflação. Usava mais uma vez a estratégia do medo (CHAIA, 2004) após sustentar que, se não cumprissem a lei, haveria retorno de prática inflacionária.
A volta da inflação é uma possibilidade; se não houver uma atenção da sociedade, do debate público nos próximos meses, o respeito à Lei de Responsabilidade Fiscal, que alguns querem modificar radicalmente com ações na Justiça e posições dessa natureza, é uma possibilidade que não pode ser eliminada (JORNAL NACIONAL, 16 de maio de 2002).

O telejornal exibiu, quase diariamente nos meses estudados, reportagens sobre um mercado financeiro nervoso com a alta do dólar e aumento de inflação, mas destacava, principalmente, o risco Brasil. Armínio Fraga, mais uma vez, declarou, no JN do dia 05 de junho, que o medo dos investidores pela proximidade das eleições estava fazendo o risco Brasil subir.

No período analisado, o Jornal Nacional também colocou críticas de Lula à economia. $\mathrm{Na}$ edição de 26/04/2002, o telejornal polemizou mostrando uma sonora de Lula sobre o aumento da alíquota de imposto de renda. A matéria foi interpretativa, quando a edição selecionou a fala e incitou os outros pré-candidatos a comentarem.

Apresentador: uma declaração do pré-candidato do PT à presidência da República, Luiz Inácio Lula da Silva, acabou provocando comentários dos outros pré-candidatos. Lula disse ontem na Assembleia Legislativa de Salvador que a alíquota do Imposto de Renda para quem ganha muito deveria aumentar, chegando até a 50\%. Lula: um cidadão que ganha $\mathrm{R} \$ 3$ mil, $\mathrm{R} \$ 4$ mil já tem que pagar $27,5 \%$. Depois se ganhar um pouco mais vai para $35 \%$, quando você poderia ter uma escala de 5\%,10\%,15\% até chegar a $50 \%$ nos altos salários. Mas deveria diminuir na base da pirâmide (JORNAL NACIONAL, 26 de abril de 2002).

Na eleição de 2002, os ministros de Estado, na época, declararam seu voto ao candidato do governo, e as matérias foram destacadas pelo Jornal Nacional, como na entrevista do ministro da educação, Paulo Renato. 
Isto é uma armação para tentar desestabilizar a candidatura dosenador JoséSerra. Não começou o debate político ainda. Infelizmente está todo mundo preocupado apenas com questões menores, como pesquisa, que neste momento final não tem nenhum valor. Ninguém está discutindo propostas para o país. Admiro o senador José Serra, tenho respeito por ele e sei da sua honestidade, e sei que é o candidato mais capacitado (JORNAL NACIONAL, 7 de maio de 2002).

O foco do noticiário político e econômico produzido pela equipe de comunicadores que integravam o JN, em 2002, foi de matérias que não evidenciavam a figura do presidente, mas expunham os representantes de governo e estimulavam a análise no mercado internacional, desviando-se dos problemas econômicos brasileiros. No que se refere ao enquadramento, percebe-se o destaque para o enquadramento temático que enfatiza posições e propostas (PORTO, 2001).

A edição do JN, no primeiro período analisado, é muito questionável porque "sugere" parcialidade ao selecionar e enquadrar depoimentos polêmicos e que poderiam contribuir negativamente para as candidaturas. O telejornal também fez edições tendenciosas usando textos opinativos e de deboche. Ao falar de Itamar Franco, que se desfiliou do PMDB, por exemplo, o apresentador Willian Bonner usou a seguinte frase em tom de ironia. "Ele já saiu do PMDB três vezes e dessa vez disse que é para sempre". A desqualificação de candidatos, nos textos, no período analisado, atribui à seleção o enquadramento centrado na personalidade que, na concepção de Porto, são: "notícias que enfatizam as características e a vida pessoal dos candidatos e outros atores" (PORTO, 2001, p. 13).

\section{Eleições 2010}

Politicamente, o cenário que se desenhou da eleição de 2010 foi mais próximo da eleição passada, em 2006. O tribunal Superior Eleitoral registrou nove pedidos de candidaturas. Entre os partidos, considerados pequenos, que tiveram candidatos à eleição majoritária em 2006: Partido Socialismo e Liberdade (PSOL), Partido Socialista dos Trabalhadores Unificados (PSTU), Partido da Causa Operária
(PCO), Partido Social Democrata Cristão (PSDC); Partido Verde (PV), que foi o destaque. A pré-candidata do PT já estava praticamente definida em 2009. Embora se tentasse levantar obstáculos para a candidatura da ex-ministra da casa civil, Dilma Rousseff, nenhum escândalo midiático como o mensalão ou valerioduto de 2005 atrapalharam. Marina Silva, também ex-ministra do governo Lula e dissidente do PT, já se garantia, com destaque da mídia, como candidata do seu novo partido: o PV; partido este que foi o destaque nas eleições municipais de 2008, quase ficando no comando da segunda maior cidade do país, o Rio de Janeiro.

A polarização das eleições de 2010 ficou por conta do PSDB, partido de maior oposição ao governo Lula. Como em 2006, o partido travou uma disputa interna para definir seu candidato e, depois, na definição do vice. José Serra mais uma vez venceu dentro do partido e disputou a eleição presidencial pela segunda vez. O PMDB, repetindo o feito de 2006, preferiu ficar de fora da candidatura à presidência, porém não ficou apenas como coadjuvante: Michel Temer, um dos principais PMDBistas aliados ao presidente Lula, disputou como vice na chapa de Dilma Rousseff.

No estudo sobre as eleições de 2010, foi utilizado o mesmo critério da pesquisa sobre as eleições de 2002, embora a amostragem tenha sido maior. No último pleito, o JN apresentou, no seu formato, algumas características diferentes em relação aos outros anos. O cenário, paginação e até o vestuário da apresentadora passaram por mudanças em 2009; por ocasião da comemoração dos 40 anos do telejornal, tudo ficou mais informal e mais próximo do telespectador; no entanto, o estilo de cobertura permaneceu o mesmo.

Nos meses de abril e maio de 2010, o telejornal destacou poucas matérias de política, enfatizou mais assuntos críticos relacionados ao governo e matérias voltadas para o comportamento, catástrofes, casos de polícia e espetacularização de episódios privados.

As notícias relacionadas ao governo Lula ressaltavam a carga tributária e exibiam matérias especiais sobre os impostos e a discussão em torno do leilão da usina de Monte Verde. No entanto, a polêmica maior ficou por conta do acordo do governo brasileiro com o Irã. Foram vários dias e várias reportagens em tom de crítica antes e durante 
a visita do presidente Lula àquele país. Só no dia 17 de maio foram apresentadas cinco matérias sobre o mesmo assunto. A média de tempo das matérias era de dois minutos, considerada expressiva para o gênero telejornal, sobretudo quando somada. Do final de maio até as proximidades da Copa do Mundo, o destaque continuou sendo as relações do Brasil com o Irã e as críticas dos países do primeiro mundo, inclusive Estados Unidos.

"Governo brasileiro pede apoio para evitar punições ao Irã por causa do programa nuclear" (JORNAL NACIONAL, 15 de abril de 2010). "Lula chega ao Irã para discutir programa nuclear" (JORNAL NACIONAL, 15 de maio de 2010).

Lula chega ao Irã para discutir programa nuclear $[\ldots]$ parlamentares se dividem sobre o acordo feito entre Brasil, Irã e Turquia [...] Liga Árabe elogia acordo anunciado em Teerã [...] EUA e Europa acham vago acordo nuclear entre Irã e Turquia [...] Países se preocupam com anúncio de enriquecimento de urânio do Irã [...] (JORNAL NACIONAL, 17 de maio de 2010).

"Apoio de Lula ao Irã repercute na imprensa internacional" (JORNAL NACIONAL, 19 de maio de 2010). "Lula defende acordo nuclear que Brasil e Turquia negociaram com o Irã" (JORNAL NACIONAL, 20 de maio de 2010). "Hillary Clinton diz que o Brasil e os Estados Unidos divergem seriamente sobre o Irã" (JORNAL NACIONAL, 27 de maio de 2010).

As críticas ao governo Lula não ficaram apenas noâmbito econômico; outros vieses buscaram reportagens que tinham problemas relacionados com o partido e o próprio presidente: "Polícia Federal prende 31 suspeitos de desviar 50 milhões de reais de verba pública - Um dos presos é Valdebran Padilha conhecido com o caso dos aloprados contra [...] era tesoureiro do PT".

Em relação às eleições, os destaques do Jornal Nacional, nos meses de abril e maio, ficaram por conta das convenções, fase da decisão das candidaturas. Em pelo menos quatro telejornais, as matérias negativas foram em relação ao pré-candidato do PSB, Ciro Gomes, que pretendia apoio do partido para lançar sua candidatura. A exemplo de Anthony Garotinho, em 2006, e do próprio Ciro, em 2002, a cobertura do telejornal para o caso foi com o objetivo de desqualificar o político, usando textos interpretativos e de deboche. A matéria que finalizou com a polêmica durou quase cinco minutos. "Ciro que pleiteia ser candidato [...], mas quer a aprovação do partido [...]" (JORNAL NACIONAL, 10 de abril de 2010). "Ciro Gomes quer se candidatar, mas o partido ainda não [...]" (JORNAL NACIONAL, 19 de abril de 2010). "Quer disputar, mais ainda não conseguiu acordo para se lançar [...]” (JORNAL NACIONAL, 20 de maio de 2010).

O PSB anunciou hoje, oficialmente, que o deputado Ciro Gomes não vai disputar a presidência da República. A decisão põe fim ao projeto de Ciro de concorrer ao cargo pela terceira vez [...]. Ex-governador, ex-ministro do governo Fernando Henrique e ex-ministro do governo Lula, mesmo assim Ciro Gomes não conseguiu ser candidato a presidente como queria [...] (JORNALNACIONAL, 27 de abril de2010).

As tentativas de multas e as multas de fato para o presidente Lula e a candidata dele Dilma Rousseff também foram focalizadas em várias reportagens. Em algumas, o destaque era a cobrança da oposição para pressionar o TSE em fixar a punição. "PSDB e DEM dizem que Lula fez propaganda antecipada de Dilma" (JORNAL NACIONAL, 5 de abril de 2010). "DEM pede punição do TSE para Lula e Dilma Rousseff" (JORNAL NACIONAL, 3 de maio de 2010). "TSE multa Dilma Rousseff e o PT" (JORNALNACIONAL, 14 de maio de 2010). "PSDB quer que TSE multe o PT, Lula e Dilma Rousseff" (JORNAL NACIONAL, 18 de maio de 2010). "Lula é multado pela terceira vez pelo TSE" (JORNAL NACIONAL, 19 de maio de 2010). "TSE mantém multa de Lula por propaganda eleitoral antecipada" (JORNAL NACIONAL, 7 de abril de 2010).

No mês de junho, como acontece em todas as eleições, embora seja um mês decisivo para acerto dos candidatos à presidência, o telejornal cedeu espaço para a cobertura da Copa do Mundo de Futebol. No entanto, em 2010 as matérias sobre eleições e economia ainda foram destaque e ficou evidente, nesse mês, o direcionamento das reportagens em benefício ao principal candidato oposicionista. Foram quatro matérias de apoio e confirmação à candidatura de José Serra, a maioria excedeu os 
quatro minutos; três matérias foram positivas para a candidata Dilma, com apoios, porém não duraram nem dois minutos. As outras duas matérias específicas sobre candidaturas foram sobre a confirmação de Marina Silva do PV e da convenção do PSOL; somando, as duas tiveram pouco mais dois minutos.

A coleta de dados e a análise desse período mostrou que, no mês de junho, outro conteúdo que apareceu sobre eleições e com ênfase negativa para o governo foi a acusação de um suposto dossiê e pagamento para espionagem do PT ao candidato do PSDB. O Jornal Nacional deu três matérias com quase cinco minutos cada uma e só não repetiu o feito de 2006 quando "espetacularizou" um suposto dossiê sobre José Serra, porque não teve espaço suficiente no telejornal.

O estudo de 2010 evidenciou a a centralização na personalidade que enfatizou os problemas individuais do presidente Lula e desqualificou suas ações. Esses aspectos foram os mais frequentes e, portanto, indicaram enquadramento diferenciado daquele estudado em 2002.

\section{O comportamento nas duas eleições: elementos comparativos}

No início da campanha eleitoral, em 2002, o telejornal, por meio do discurso imagético e verbal, enfatizou o medo da mudança. O discurso do então candidato do governo José Serra, de políticos e membros do governo Fernando Henrique, apontando que o Brasil poderia se transformar em uma "Venezuela" ou "Argentina", caso o novo governo tomasse outros rumos, foi significativo e expressivo. O Fundo Monetário Internacional (FMI), quanto a garantias de que o novo governo honraria os compromissos, e o aumento do "risco Brasil" foram os destaques das matérias da mídia e, principalmente, do Jornal Nacional.

$\mathrm{Na}$ análise da cobertura dada pelo Jornal Nacional à eleição presidencial de 2002, pôde-se concluir que o telejornal exerceu um papel fundamental no processo eleitoral, ao suscitar debates, exibir matérias pertinentes e levantar problemas. Além disso, o destaque balanceado demonstrou interesse na isenção e em apagar a imagem parcial a qual o telejornal carregava, porém identificamos que os candidatos não tiveram o mesmo tratamento e os editores destacaram suas preferências, fazendo uma cobertura parcial.

Em 2002, os candidatos de oposição eram considerados desestabilizadores de um projeto econômico estável, mas com elevados impostos e taxas de juro, aliados à falta de estrutura. Essa abordagem foi evidenciada em matéria veiculada em junho de 2010 sobre o Produto Interno Bruto (PIB) e o maior superávit desde 1995. Os parlamentares opinaram, o que neutralizou a perspectiva otimista do governo e indicou valência negativa.

Em relação ao candidato de oposição, identificou-se que, ao contrário de 2002, José Serra, no primeiro período analisado em 2010, recebeu maior visibilidade como oposição do que quando era governo. As reportagens do Jornal Nacional exibiram festas nas convenções, confirmações nas candidaturas e visibilidade positiva. Cada matéria, só no mês de junho, teve quase cinco minutos.

Embora historicamente a mídia tenha apoiado, por interesses vários, candidatos que representem o governo, em 2010, conforme demonstrou este estudo, as matérias apresentadas pelo Jornal Nacional foram carregadas de hostilidade em relação ao governo Lula. Rubim (2007) atesta que o governo Lula nunca teve apoio da mídia como Fernando Henrique Cardoso: houve tão somente certo apoio conjuntural pela tradição governista de alguns veículos. Os resultados da pesquisa feita para o artigo vêm comprovar a hipótese já levantada em outros estudos (NEVES, 2008) sobre a sutileza do Jornal Naiconal para possibilitar um agendamento da opinião pública e favorecer candidaturas.

\section{Referências}

ALDÉ, A. As eleições presidenciais de 2002 nos jornais. In: ENCONTRO INTERNACIONAL DE ESTUDOS DE MÍDIA E ELEIÇÕES, 3., 2002, Salvador. Anais... Salvador: FACOM; UFBA, 2002.

CHAIA, V. Eleições no Brasil: o medo como estratégia política. In: RUBIM, A. A. C. (Org.). Eleições presidenciais em 2002 no Brasil. São Paulo: Hacker, 2004.

COLLING, L. Agendamento, enquadramento e silêncio no Jornal Nacional nas eleições presidenciais de 1998. 2000. Dissertação (Mestrado em Comunicação e Cultura Contemporânea) - Faculdade de Comunicação, Universidade Federal da Bahia, Salvador, 2000. 
ENTMAN, R. Framing: toward classification of a factured paradigm. Journal of Communication, v. 18, n. 4, p. 51-58, 1993.

JABOR, A. Jornal Nacional. Rio de Janeiro: Rede Globo, 26 abr. 2002. Programa de televisão.

JORNAL NACIONAL. Rede Globo de Televisão. 26 abr. 2002; 7, 8, 13, 16 maio 2002; 5 jun. 2002, 5, 7, 10, 15, 19, 27 abr. 2010; 3, 14, 15, 17, 18, 19, 20, 27 maio 2010.

NEVES, F. Telejornalismo e poder nas eleições presidenciais de 2002 e 2006. São Paulo: Summus, 2008.

PORTO, M. P. A mídia brasileira e a eleição presidencial de 2000 nos EUA: a cobertura do jornal Folha de S. Paulo. Cadernos do CEAM, v. 2, n. 6, p. 11-32, 2001.

RUBIM, A. A. C. Ética da política e ética na política nas eleições de 2006. In: LIMA, V. (Org.). A mídia nas eleições de 2006. São Paulo: Fundação Perseu Abramo, 2007.

Recebido: 11/04/2011

Received: 04/11/2011

Aprovado: 06/06/2011

Approved: 06/06/2011 